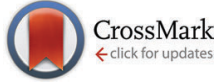

Cite this: J. Mater. Chem. B, 2016, 4, 5673

\title{
Co-operative transitions of responsive-polymer coated gold nanoparticles; precision tuning and direct evidence for co-operative aggregation $\dagger$
}

\begin{abstract}
Sangho Won, ${ }^{a}$ Daniel J. Phillips, ${ }^{a}$ Marc Walker ${ }^{\mathrm{b}}$ and Matthew I. Gibson ${ }^{\text {ac }}$
Responsive polymers and polymer-coated nanoparticles have many potential bio-applications with the crucial parameter being the exact temperature where the transition occurs. Chemical modification of hydrophobic/hydrophilic or ligand binding sites has been widely explored as a tool for controlling this transition, but requires the synthesis of many different components to achieve precise control. This study reports an extensive investigation into the use of blending (i.e. mixing) as a powerful tool to modulate the transition temperature of poly( $\mathrm{N}$-isopropylacrylamide) (PNIPAM) coated gold nanoparticles. By simply mixing two nanoparticles of different compositions, precise control over the transition temperature can be imposed. This was shown to be flexible to all possible mixing parameters (different polymers on different particles, different polymers on same particles and different sized particles with identical/different polymers). Evidence of the co-operative aggregation of differently sized nanoparticles (with different cloud points) is shown using transmission electron microscopy; particles with higher cloud points aggregate with those with lower cloud points with homo-aggregates not seen, demonstrating the co-operative behaviour. These interactions, and the opportunities for transition tuning will have implications in the rational design of responsive biomaterials.
\end{abstract}

Received 28th May 2016,

Accepted 2nd August 2016

DOI: $10.1039 / \mathrm{c} 6 \mathrm{tb} 01336 \mathrm{~h}$

www.rsc.org/MaterialsB

\section{Introduction}

Stimuli-responsive polymers can change their conformation and hence properties when external stimuli, such as temperature, ${ }^{1}$ $\mathrm{pH}^{2}{ }^{2}$ light, ${ }^{3}$ ions, ${ }^{4}$ electric, ${ }^{5}$ magnetic field ${ }^{6}$ and biochemical agents $^{7}$ are applied. These unique properties and abilities have been formulated with polymers for various biomedical fields in a number of forms including simple polymer solutions, ${ }^{8}$ hydrogels, ${ }^{9}$ micelles, ${ }^{10}$ films and layers. ${ }^{11}$ Especially, thermo-responsive polymers are the most commonly used for both in vitro ${ }^{12}$ and in vivo ${ }^{13}$ biomedical applications. Thermo-responsive polymers in solution display a lower critical solution temperature (LCST) or upper critical solution temperature (UCST). The LCST is the point where the polymer phase separates such that the polymer solution is miscible below the critical temperature whereas polymer solution is immiscible (precipitates) above it.

Poly( $N$-isopropylacrylamide) (PNIPAM) is one of the most well-known temperature-responsive polymers. ${ }^{14,15}$ In general, the LCST transition of PNIPAM is observed to be between $30{ }^{\circ} \mathrm{C}$

\footnotetext{
${ }^{a}$ Department of Chemistry, University of Warwick, Coventry, CV4 7AL, UK. E-mail:M.I.Gibson@warwick.ac.uk

${ }^{b}$ Department of Physics, University of Warwick, Coventry, CV4 7AL, UK

${ }^{c}$ Warwick Medical School, University of Warwick, Coventry, CV4 7AL, UK

$\dagger$ Electronic supplementary information (ESI) available. See DOI: 10.1039/c6tb01336h
}

to $45{ }^{\circ} \mathrm{C} .{ }^{16}$ Several factors including molecular weight, ${ }^{17}$ terminal group of the polymer ${ }^{18}$ polymer concentration, ${ }^{19} \mathrm{pH}$ in solution and the presence of salt $^{20}$ as well as self assembly ${ }^{21}$ have significant effects on the observed transition temperatures.

By employing RAFT (reversible addition fragmentation and transfer) polymerization, pNIPAM (and indeed many other classes of polymers) can be directly incorporated onto the surface of gold nanoparticles due to the quantitative installation of a (masked) thiol at each $\alpha$-chain end. Responsive polymer coated gold nanoparticles retain sensitivity to external stimuli $^{22}$ and can be applied in wide range of therapeutic applications including a catalysis, diagnosis, imaging and photoelectronic device. ${ }^{23,24}$ It has been reported that PNIPAM coated gold nanoparticles can be used to drive cellular uptake upon increasing the temperature above the solution temperature due to a shift in the lipophilicity of the particle promoting membrane interactions ${ }^{24 a, 25}$ and is an attract route to gain entry into cells for delivery applications. However, to achieve this (or other) goals, precise control over the transition temperature is essential. It has been reported by Fernández-Trillo et al. that the cloud point of elastin-mimetic polymers could be tuned by simple mixing polymers with different cloud points. ${ }^{26}$ This has been shown to be the case for some polymers but also polymergrafted nanoparticles. ${ }^{27}$ However, other classes of polymers failed to show any co-operativity with distinct 'steps' seen in 
mixtures of polymers such as elastin peptides or poly(oligo[ethyleneglycol methacrylates]) implying this is a unique property. ${ }^{28}$

The above raises questions about the scope of the blending approach but also the mechanism - for a single transition to occur, the particle/polymer with the higher cloud point must preferentially interact with the particle/polymer with a lower cloud point (otherwise it would not aggregate at temperatures below its own transition temperature). This implies a more complex inter-relationship between the entities than is often considered, and thus far there is no direct evidence of these interactions, as only turbidimetry is employed.

In this manuscript, the co-operative aggregation of PNIPAM coated nanoparticles is studied in detail and the limits and scope of the blending (using all possible mixing parameters of particles and polymers) is studied using a range of techniques. Crucially, the size-dependant co-operative transitions are studied using electron microscopy, enabling the identity of each interacting component to be assigned to direct observe the cooperativity for the first time.

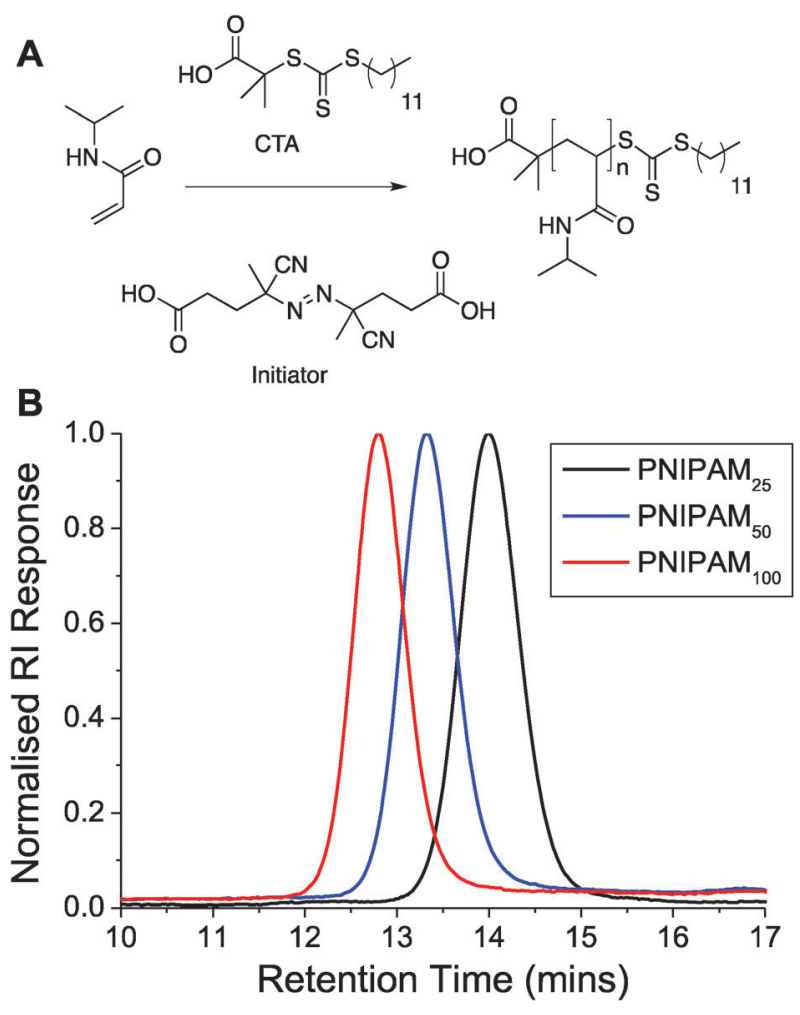

Fig. 1 (A) Synthetic route to PNIPAMs; (B) SEC analysis of polymers.

\section{Results and discussion}

To access the range of well-defined PNIPAM's required for this study RAFT (reversible addition fragmentation chain transfer) polymerization was employed, Fig. 1A. A trithiocarbonate RAFT agent was chosen, and synthesized, based on its reported utility for control over the RAFT polymerization, which also inserts the desired thiol end-group for later immobilization onto gold nanoparticles. NIPAM was polymerized in dioxane and following isolation by precipitation was characterized by ${ }^{1} \mathrm{H}$ and ${ }^{13} \mathrm{C}$ NMR and SEC (size exclusion chromatography). SEC confirmed a controlled polymerization with narrow dispersity values and the observed molecular weights agreeing well with those predicted from the monomer : initiator feed ratio, Table 1 and Fig. 1 . The polymers are labelled from here based on their targeted degree of

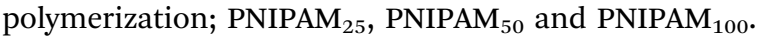

The polymers were then evaluated for their thermo-responsive behavior both in water and in saline, as this is crucial for the measurements later in this manuscript as 'grafted to' gold nanoparticle polymer hybrids require salt to screen their overall net negative charge (vide infra). UV-Vis spectroscopy was used to determine the CP (cloud point) of polymer defined as being the point of $50 \%$ transmittance and the results of this (at $2.5 \mathrm{mg} \mathrm{mL}^{-1}$ ) are shown in Table 2. (Note, the cloud point is distinct from, and is the macroscopic effect associated with, an LCST). In water the polymers all had CPs from $30-38{ }^{\circ} \mathrm{C}$ as expected, but in buffer an unexpectedly high cloud point was observed with the shortest polymer having a transition above $60{ }^{\circ} \mathrm{C}$. We ascribed this to partial self assembly of the shortest polymers into micelles due to the hydrophobic end group, and hence the transitions are for nanostructures rather than the polymers, but is outside of the scope of this study (focused on the nanoparticles, vide infra). To probe any co-operative effects, a pair of polymers having

Table 2 Cloud points for each polymer and polymer mixture in different media

\begin{tabular}{|c|c|c|c|}
\hline Polymer & $\begin{array}{l}\text { Weight } \\
\text { fraction [\%] }\end{array}$ & $\begin{array}{l}\text { Cloud } \\
\text { point }_{\text {water }}{ }^{a}\left[{ }^{\circ} \mathrm{C}\right]\end{array}$ & $\begin{array}{l}\text { Cloud } \\
\text { point }_{\mathrm{PBS}}{ }^{b}\left[{ }^{\circ} \mathrm{C}\right]\end{array}$ \\
\hline PNIPAM $_{25}$ & 100 & 33 & 61 \\
\hline PNIPAM $_{50}$ & 100 & 36 & 47 \\
\hline PNIPAM $_{100}$ & 100 & 38 & 41 \\
\hline PNIPAM $_{50}:$ PNIPAM $_{100}$ & $25: 75$ & - & 42 \\
\hline PNIPAM $_{50}:$ PNIPAM $_{100}$ & $50: 50$ & - & 43 \\
\hline PNIPAM $_{50}:$ PNIPAM $_{100}$ & $75: 25$ & - & 45 \\
\hline
\end{tabular}

Cloud point was measured in ${ }^{a}$ pure water and ${ }^{b}$ PBS buffer upon heating from $25{ }^{\circ} \mathrm{C}$ to $85{ }^{\circ} \mathrm{C}, 2.5 \mathrm{mg} \mathrm{mL} \mathrm{m}^{-1}$ polymer concentration. CPs of PNIPAM mixture were not measured in water due to the very narrow gap between each polymers CP.

Table 1 Characterisation of polymers

\begin{tabular}{lllllll}
\hline Polymer & {$[\mathrm{M}] /[\mathrm{CTA}] /[\mathrm{I}][\mathrm{mol}]$} & $M_{\mathrm{n} \text { Target }}\left[\mathrm{g} \mathrm{mol}^{-1}\right]$ & Conversion $^{a}[\%]$ & $M_{\mathrm{n}}$ Theo $^{b}\left[\mathrm{~g} \mathrm{~mol}^{-1}\right]$ & $M_{\mathrm{n} \mathrm{seC}}{ }^{c}\left[\mathrm{~g} \mathrm{~mol}^{-1}\right]$ & $M_{\mathrm{w}} / M_{\mathrm{n}}[-]$ \\
\hline PNIPAM $_{25}$ & $25 / 1 / 0.2$ & 2800 & 87 & 2500 & 2900 \\
PNIPAM $_{50}$ & $50 / 1 / 0.2$ & 5700 & 84 & 4800 & 4900 \\
PNIPAM $_{100}$ & $100 / 1 / 0.2$ & 11300 & 72 & 8100 & 7700
\end{tabular}

$\operatorname{PNIPAM}_{x x x}=\operatorname{poly}\left(N\right.$-isopropylacrylamide) where average degree of polymerization indicated by $x x x .{ }^{a}$ Determined ${ }^{1} \mathrm{H}$ NMR. ${ }^{b}$ Calculated from the [monomer]: [CTA] ratio and of conversion. ${ }^{c}$ Determined by SEC in DMF using PMMA standards. 


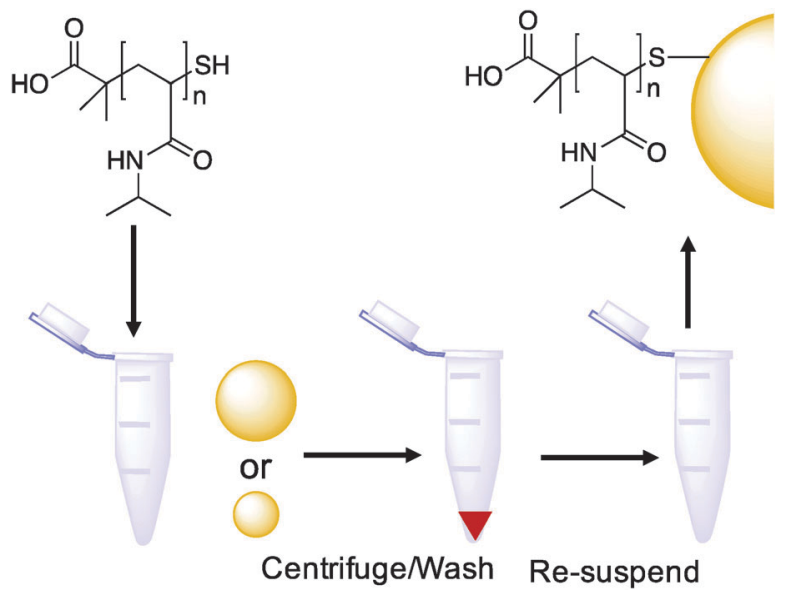

Scheme 1 Synthesis of thermo-responsive polymer (PNIPAM) and polymer/gold hybrid nanoparticles.

different molecular weights below $\sim 10 \mathrm{~kg} \mathrm{~mol}^{-1}$ were tested as PNIPAM does not have a strong molecular weight dependence on its LCST above this value. ${ }^{29}$ PNIPAM $_{50}(4.9 \mathrm{kDa})$ and PNIPAM $_{100}$ (7.7 kDa) were prepared at $2.5 \mathrm{mg} \mathrm{mL}^{-1}$ in PBS solution. Table 2 also shows transition temperature for blends of PNIPAM $_{50}$ and PNIPAM $_{100}$ at various weight fraction compositions. There are two independent transition temperature of each pure polymer, PNIPAM $_{50}$ has a transition temperature of $47^{\circ} \mathrm{C}$ whereas PNIPAM 100 has a transition temperature of $41^{\circ} \mathrm{C}$. Blends of these polymers at all weight fractions shows a clear transition between $41-47^{\circ} \mathrm{C}$. The CPs of polymer mixture were shifted towards higher as increasing

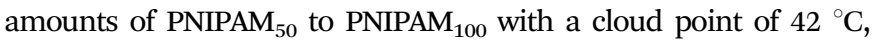
$43{ }^{\circ} \mathrm{C}$ and $45{ }^{\circ} \mathrm{C}$, respectively.

With the function of the polymers and their co-operative nature confirmed, PNIPAM coated gold nanoparticles were synthesized as shown in Scheme 1. Briefly, the RAFTed polymers were mixed onto pre-made citrate stabilized gold nanoparticles by a simple mixture procedure, which we have used previously. Excess polymer was removed by repeated centrifugation samples to ensure only polymer-coated nanoparticles were investigated and not free polymer (Table 3).

The nanoparticles were characterized by a range of techniques including TEM, DLS and XPS. The hydrodynamic diameter of

Table 3 Characterization of the polymer coated nanoparticles

\begin{tabular}{llll}
\hline Particle $^{a}$ & SPR $_{\max }[\mathrm{nm}]$ & $d_{\mathrm{DLS}}{ }^{b}[\mathrm{~nm}]$ & Cloud point $^{c}\left[{ }^{\circ} \mathrm{C}\right]$ \\
\hline Bare Au 15 nm $^{15}$ & 520 & 18 & - \\
PNIPAM $_{25} @ A u_{15}$ & 524 & 24 & - \\
PNIPAM $_{50} @ \mathrm{Au}_{15}$ & 524 & 32 & 74 \\
PNIPAM $_{100 @ A u} @$ & 525 & 37 & 55 \\
Bare Au 40 nm & 526 & 42 & - \\
PNIPAM $_{25} @ \mathrm{Au}_{40}$ & 530 & 50 & - \\
PNIPAM $_{50} @ \mathrm{Au}_{40}$ & 531 & 56 & 80 \\
PNIPAM $_{100} @ \mathrm{Au}_{40}$ & 531 & 61 & 60
\end{tabular}

${ }^{a} \mathrm{X} @ \mathrm{Au}_{m}: \mathrm{X}=$ polymer coating used; $m=$ diameter of gold nanoparticle. ${ }^{b} d_{\text {DLS }}(\mathrm{nm}): Z$-average diameter as determined by DLS. ${ }^{c}$ Measured in PBS upon heating from $25{ }^{\circ} \mathrm{C}$ to $85{ }^{\circ} \mathrm{C}, 0.029 \mathrm{mg} \mathrm{mL}^{-1}$ total gold concentration. uncoated gold nanoparticles was $18 \mathrm{~nm}$ and $42 \mathrm{~nm}$ by DLS measurements while after PNIPAM coating diameter were increased to $37 \mathrm{~nm}$ and $61 \mathrm{~nm}$, respectively confirming the surface-tethering of the polymer chains. The surface plasmon resonance bands were also red shifted to longer wavelengths from 520 to $525 \mathrm{~nm}$ for $18 \mathrm{~nm}$ gold nanoparticles and 526 to $531 \mathrm{~nm}$ for $42 \mathrm{~nm}$ gold nanoparticles consistent with successful functionalisation. The particles were also imaged by TEM after functionalization with the polymers (the non-coated particles tended to aggregate on the TEM grid, see Fig. S6, ESI $\dagger$ ). A uniform distribution of spherical core nanoparticles with an average particle size of $15.2 \pm 1.4 \mathrm{~nm}$ and $40.7 \pm 4.0 \mathrm{~nm}$ were observed in TEM and there was no evidence of agglomeration or ripening of the gold (Fig. 2).

Additional characterisation was conducted using surface X-ray photoelectron spectroscopy (XPS) using gold particles deposited on silicon supports. As can be seen in Fig. 3, both carbon (C1s) and nitrogen (N1s) region (at around $399.7 \mathrm{eV}$ ) of the spectra for the PNIPAM coated gold nanoparticles is broader than the bare gold nanoparticles. This is due to the $\mathrm{C}-\mathrm{N}$ peak at around $286.2 \mathrm{eV}$. The presence of the $\mathrm{C}=\mathrm{O}$ peak at around $287.8 \mathrm{eV}$ indicates clear evidence of the presence of PNIPAM on the gold surface. Also, the intensity of both carbon and nitrogen peak increased higher after conjugation of longer PNIPAM polymer chain because of the higher concentration of carbon and nitrogen are incorporated in longer PNIPAM chain.

The PNIPAM@Au particles could now be tested for their responsive behaviour. As reported by Hoogenboom et al. ${ }^{30}$ in water no transition was seen in the temperature range tested $\left(25-85{ }^{\circ} \mathrm{C}\right)$, but when repeated in PBS a clear transition could be seen. These observations were attributed to the residual citrate on the nanoparticle surface, which was still negative charged (measured by zeta-potential) even after polymer coating, but approached neutrality in PBS. Fig. 4B shows the effect of heating the particles in PBS above their CP, with a clear red shift (long wavelength) in their absorption spectra, with an increase at $700 \mathrm{~nm}$ and red-blue colour shift. Aggregation was further confirmed by variable temperature DLS which showed an increase in hydrodynamic diameter above the transition temperature due to increased hydrophobicity of the particles (ESI $\dagger$ ).

The main aim of this study was to probe, and provide direct evidence for, the co-operative LCST transitions of polymer coated gold nanoparticles as a route to not only fine-tune their transition temperatures but also a way to enhance biosensing or generate complex assemblies of mixed particles. We have previously shown that PNIPAM homopolymers and various soft and hard nanoparticles show 'co-operative LCST' behaviour, but the scope and limitations of this property has not been fully investigated nor direct evidence for non-identical polymers or particles interacting. ${ }^{27,31}$ To probe the potential for mixing, we investigate here a range of different combinations of polymers and nanoparticles. Firstly, PNIPAM $_{50}$ and PNIPAM 100 were immobilised onto $\mathrm{Au}_{15}$. These nanoparticles solutions were then mixed with different weight ratio of $25: 75,50: 50$ and $75: 25$ respectively and their responsive transitions measured by UV-Vis, Fig. 5A. For the above mixtures, in each case a single 
A

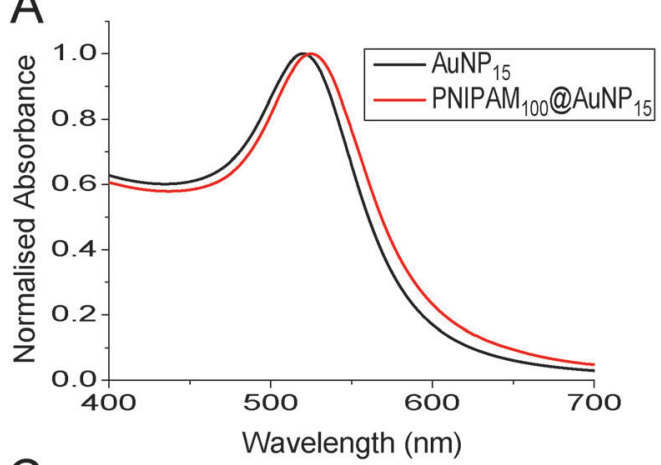

$\mathrm{C}$

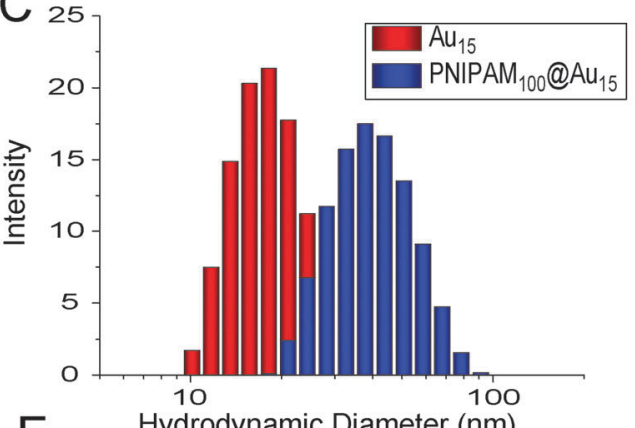

E Hydrodynamic Diameter $(\mathrm{nm})$

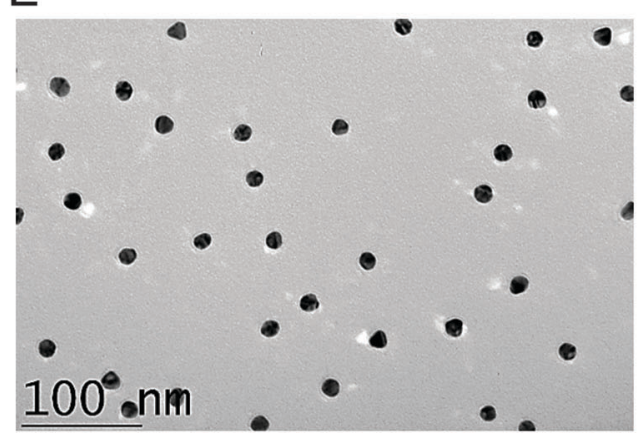

B
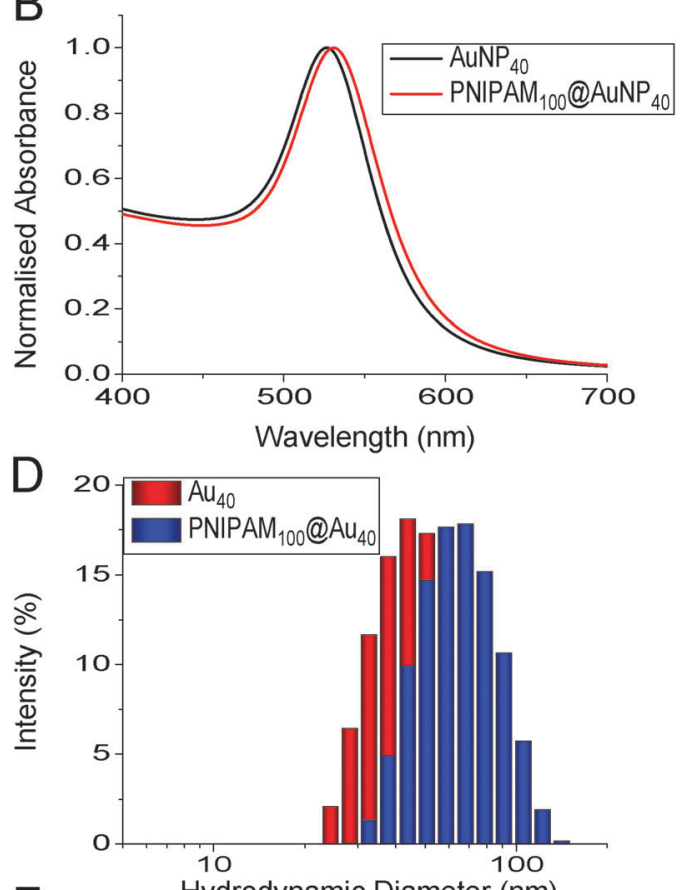

$\mathrm{F}$

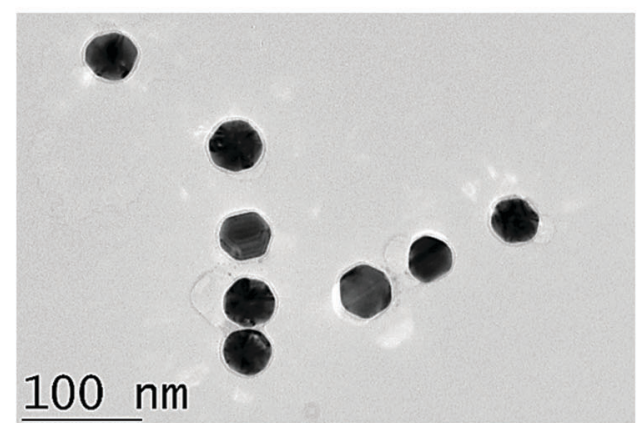

Fig. 2 Size characterization of PNIPMA100@Au15 and NIPAM100@Au40 nanoparticles. (A + B) UV-Vis analysis before and after polymer coating; (C + D) DLS analysis before and after polymer coating; $(E+F)$ TEM of polymer coated gold nanoparticles.
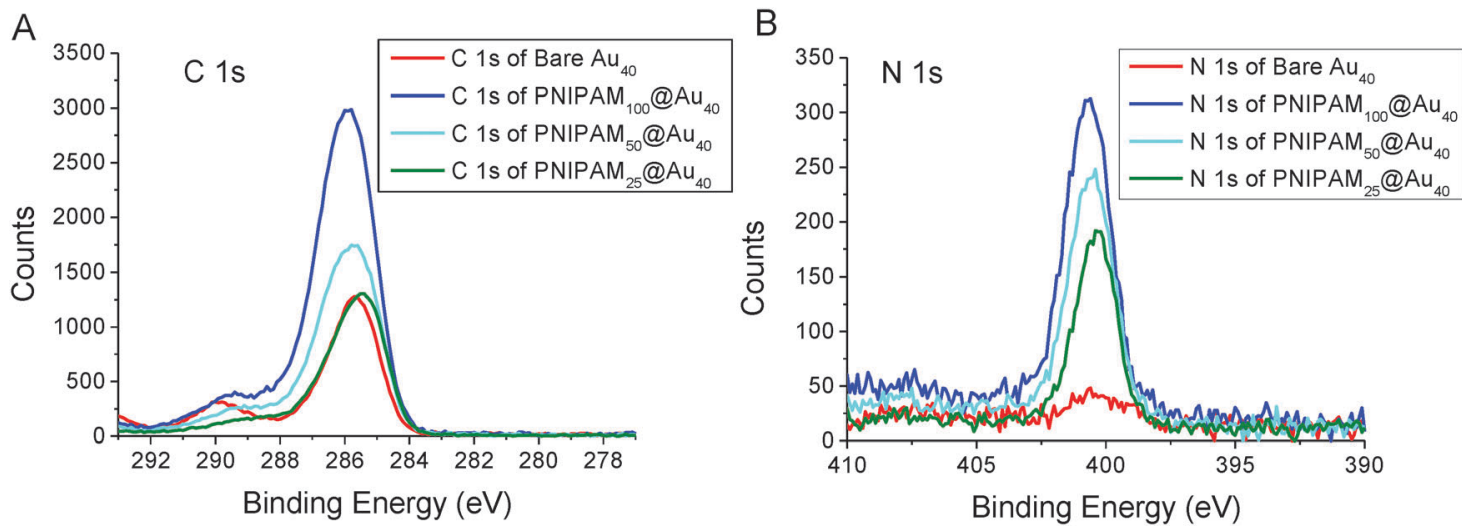

Fig. 3 X-ray photoelectron spectroscopy analysis of PNIPAM functionalized gold nanoparticles. Representative high-resolution XPS spectrum of C1s and N1s region before and after various PNIPAM conjugation. (A) Carbon (C1s) peak and (B) nitrogen (N1s) peak from the XPS analysis of polymer/gold hybrid nanoparticles.

transition temperature was observed which fell between that of the pure gold nanoparticles, and controlled by the mass fraction of the constituent components. If independent transitions were occurring, two separate transitions would be expected, 

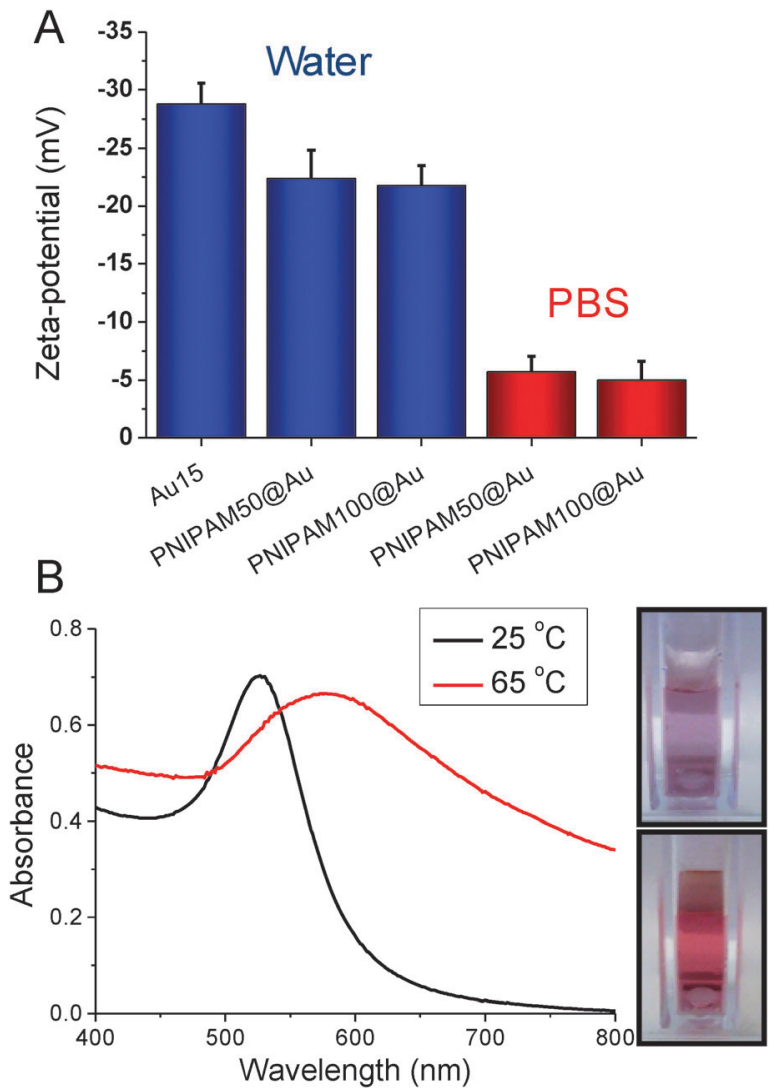

Fig. 4 Solution properties of polymer coated nanoparticles. (A) Zetapotential analysis of nanoparticles in water, and in phosphate buffered saline; (B) example UV-Vis spectra showing effect of heating above the transition temperature. Inset images show red-blue colour shift upon aggregation and the particle with a lower LCST would not see a shift in its aggregation. This is also the first example of co-operative aggregation of nanoparticles with different coatings and implies that their responsive transitions involve interaction between the different sized nanoparticles rather than isolated events. As a control experiment, the same PNIPAMs were first mixed in the same weight ratios as above $(25: 75,50: 50$ and $75: 25)$ and then added to the surface gold particles following the same procedure as described above. Whilst the homopolymer coated gold nanoparticles have sharp transition temperature of $55{ }^{\circ} \mathrm{C}$ and $74{ }^{\circ} \mathrm{C}$, respectively. The $\mathrm{CP}$ of each particle conjugated with pre-mixed polymer lying between that of the two pure polymer coated nanoparticles are shown in Fig. 5B and in agreement with what was seen in the single component nanoparticles mixtures. Taken together this shows that the transition of nanoparticles is highly dependant on the whole mixture and that more complex interactions between particles of different coatings take place.

The above data confirms that co-operativity occurs, in that the observed transitions temperatures are shifted. For this hypothesis to be true, it must be that the lower LCST particles preferentially interact (or aggregate) with the higher LCST ones, or else the transition would not be affected. To enable us to probe and visualise this directly, a different co-operative system was required which enables discrimination between particles. Therefore mixtures of differently sized nanoparticles were chosen, as this would give a measurable about in the TEM imaging (vide infra). As shown in Fig. 6A, with the same polymer PNIPAM 100 coating, transition of $15 \mathrm{~nm}$ gold nanoparticles occurs at $55{ }^{\circ} \mathrm{C}$, while $40 \mathrm{~nm}$ gold nanoparticles shifted the transition to $60{ }^{\circ} \mathrm{C}$. The solution containing a 50:50\% mixture of the particles shows a single transition at $57^{\circ} \mathrm{C}$. Fig. 6B shows turbidimetry scans for blends of different particle with the different polymer coating. The PNIPAM 100 coated $40 \mathrm{~nm}$ gold nanoparticle had an
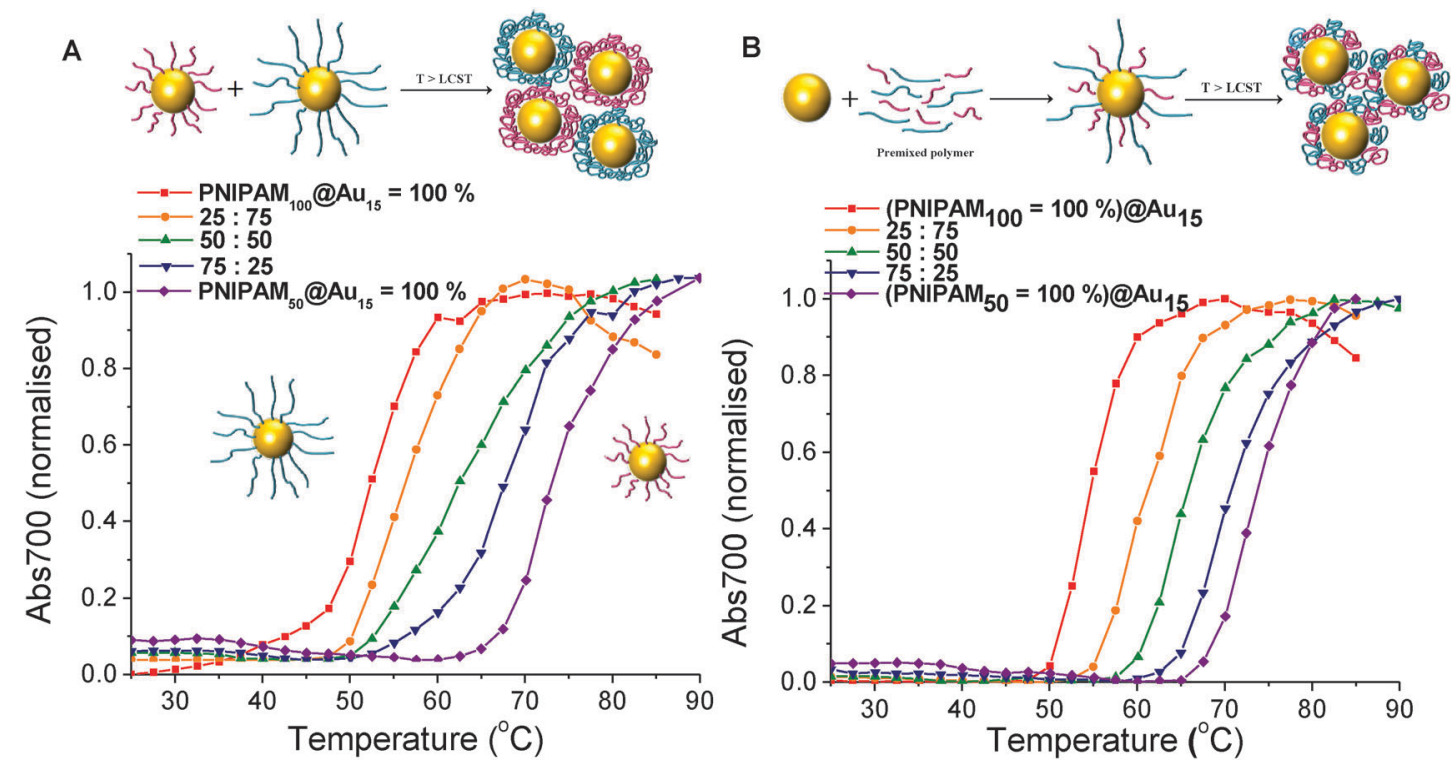

Fig. 5 Turbidimetry scans (absorbance at $700 \mathrm{~nm}$ ) of (A) PNIPAM ${ }_{50} @ A u_{15}$ and PNIPAM $100 @ A u_{15}$ mixture of the particles with different mass fraction, (B) pre-mixture of PNIPAM 50 and PNIPAM 100 with different mass fraction coated $\mathrm{Au}_{15}$ in PBS solution. In all cases the total gold core concentration of the solutions was $0.029 \mathrm{mg} \mathrm{mL}^{-1}$. 
A
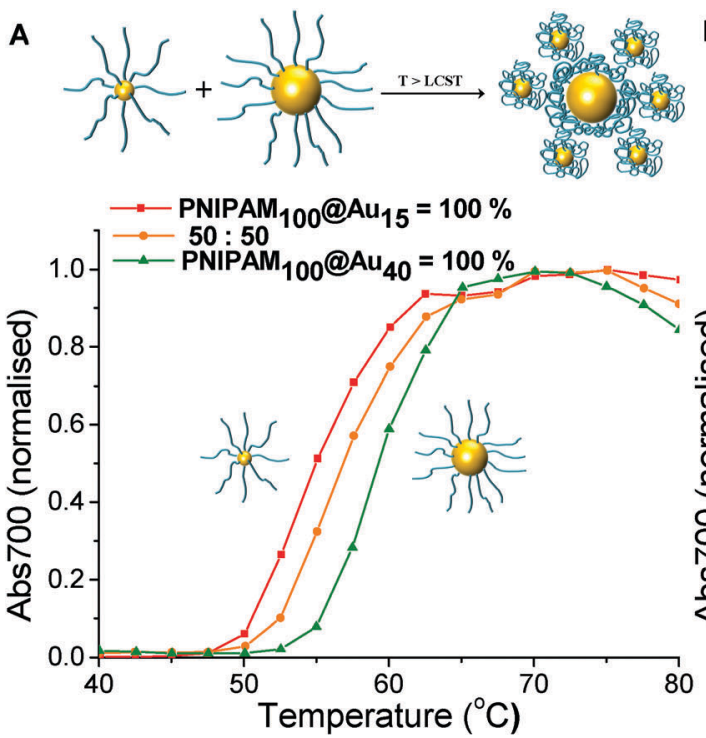

B
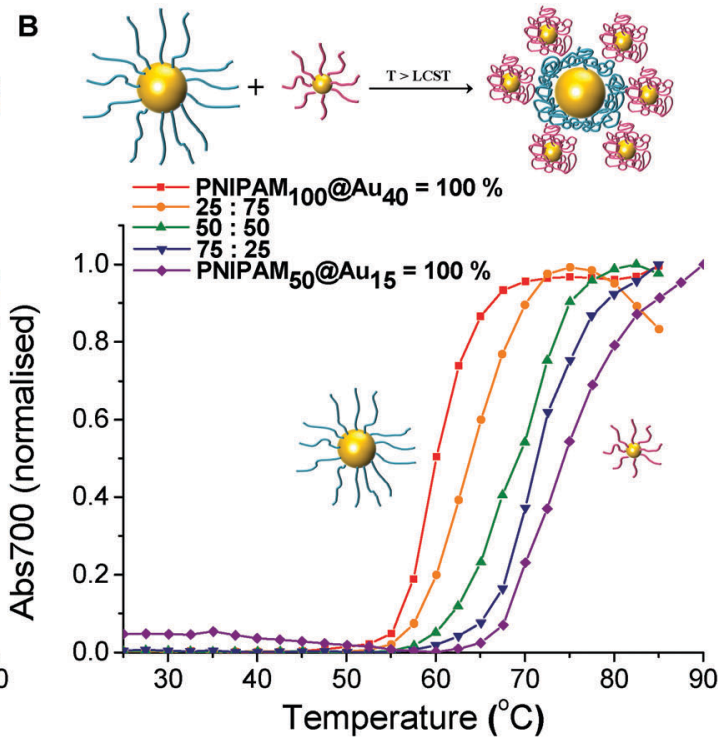

Fig. 6 Turbidimetry scans (absorbance at $700 \mathrm{~nm}$ ) of (A) blends with different mass fraction of PNIPAM 100 coated $\mathrm{Au}_{15}$ and $\mathrm{Au}_{40}$, (B) PNIPAM ${ }_{50} @ \mathrm{Au}_{15}$ and $\mathrm{PNIPAM}_{100} @ \mathrm{aAu}_{40}$ mixture with different mass fraction in PBS solution. In all cases the total gold core concentration of the solutions was $0.029 \mathrm{mg} \mathrm{mL}^{-1}$.

LCST of $60{ }^{\circ} \mathrm{C}$, whereas the PNIPAM $_{50}$ coated $15 \mathrm{~nm}$ gold nanoparticle had an LCST of $74^{\circ} \mathrm{C}$. LCSTs of particle mixture for $25: 75 \%, 50: 50 \%$ and $75: 25 \%$ with relative weight percent of PNIPAM 50 coated $15 \mathrm{~nm}$ gold nanoparticles and PNIPAM 100 coated $40 \mathrm{~nm}$ gold nanoparticles were measured. In all cases, a single transition of particle mixture was observed $64{ }^{\circ} \mathrm{C}, 69^{\circ} \mathrm{C}$ and $72{ }^{\circ} \mathrm{C}$, showing that LCST is controlled by the relative weight fraction of each particles. This result proved process successfully and the LCST of mixture particle solution is determined as a consequence of relative weight proportion of individual polymer coated nanoparticles. This strategy can be useful to control and predict LCSTs of polymer coated nanoparticles for desired condition.

The above data shows the highly co-operative nature of the nanoparticle transitions, but to it is desirable to be able to quantify the co-operativity and provide direct evidence that different nanoparticles are actually interacting preferentially with their partners. Fig. 7 shows a scheme of the possible outcomes which would be expected for co-operative and noncooperative transitions with different size/CP particles. In the non-cooperative case, heating above the $\mathrm{CP}$ of the smaller particle (lower $\mathrm{CP}$ ) would be expected to only lead to aggregates of small particles forming, as the larger (higher $\mathrm{CP}$ ) particles would still be well dispersed. Conversely, if co-operative aggregation was occurring, then mixed aggregates containing both particles should be formed, explaining the modulation. To probe this effect a range of nanoparticle samples (both pure and mixed) were prepared at a range of temperatures both below the $\mathrm{CP}$ but also at the $\mathrm{CP}$. By choosing at temperature at the CP the larger gold nanoparticles (with high CPs) if they are not interacting should not aggregate at this temperature, providing a read out for the co-operativitiy. A range of mixtures were prepared of PNIPAM $_{100} @ A_{15}:$ PNIPAM $_{100} @ A u_{40}$ with weight ratios of $3: 1,1: 1$ and $1: 3$ at both $25{ }^{\circ} \mathrm{C}$ and $58{ }^{\circ} \mathrm{C}$ (i.e. below and at $\mathrm{CP}$ ) and the TEM images are shown in Fig. 8 and Fig. S8 in the ESI. $\dagger$

Fig. 8 revealed that in the mixed nanoparticle solutions, mixed aggregates are forming containing both small and large particles, rather than just those of the lower CP material, which would be expected in a non-cooperative environment as

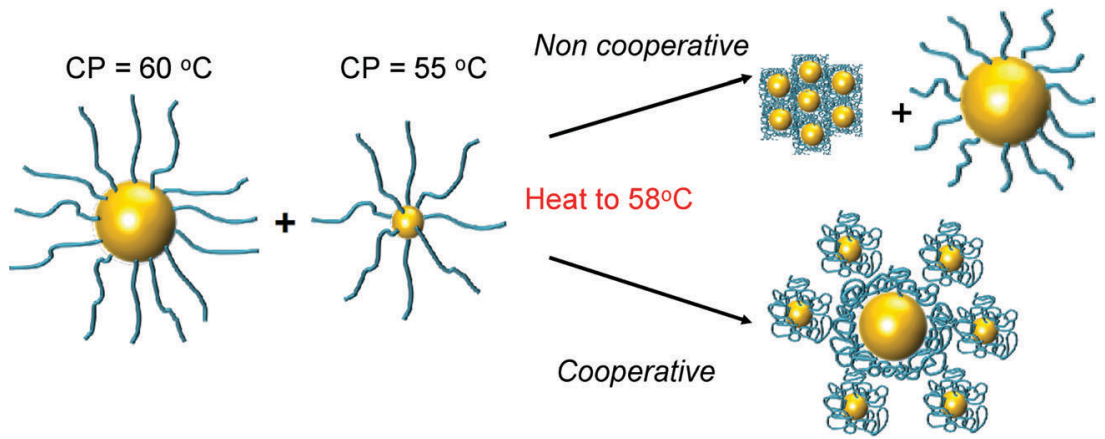

Fig. 7 Schematic to show co-operative and non-cooperative aggregates expected to guide TEM analysis (below). 

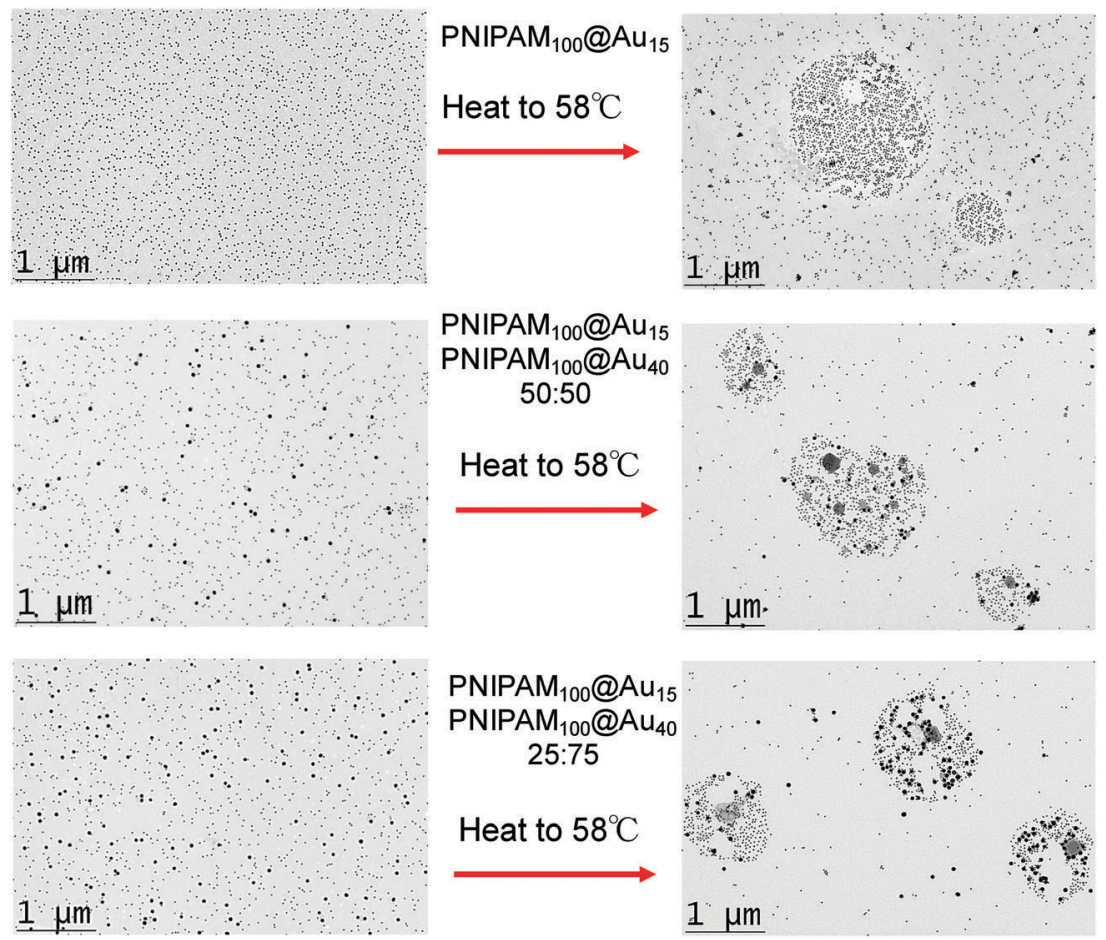

Fig. 8 TEM analysis of co-operative particle aggregation. Left hand column shows nanoparticles at $25^{\circ} \mathrm{C}$ (below their cloud point) and right hand column shows the same particles which were prepared at $58{ }^{\circ} \mathrm{C}$, above cloud point of the $15 \mathrm{~nm}$ particles, but below that of the $40 \mathrm{~nm}$ particles.

the temperature was below the aggregation temperature of the high CP material. It should be noted that particles generated with other polymer coatings, or with higher/lower grafting densities may not show the same behaviour, as we have reviewed in detail previously. ${ }^{31}$ For instance, the grafting to approach may provide sufficiently spaced polymers that inter-rather than intra particle interactions dominate and hence leading to the observations made here.

In addition to be a useful method for fine-tuning transition temperatures this shows that the particles aggregation is clearly dependant on the other particles which they are in contact with and may offer opportunities particularly in biosensing where the aggregation of a small fraction of a sample could be enhanced by other, non-interacting fractions of particles. This approach also shows that post-synthesis, obtaining an incorrect (or non-desired) transition temperature can be overcome though simple mixing.

\section{Conclusions}

Here we have investigated the co-operative aggregation of a range of thermo-responsive polymer coated gold nanoparticles. It was shown that these particles were tolerant to almost all possible mixing parameters to still produce a single transition; (i) different polymers on same sized particles, (ii) mixture of polymers on same sized particles, (iii) same polymer on different sized particles and (iv) different polymers on different sized particles in all cases enabling a route to fine-tune the transition temperature. Crucially, using the co-operative aggregation of differently sized nanoparticles it was possible to obtain evidence for the interaction of large/small nanoparticles with different cloud points via the formation of mixed aggregations in TEM, rather than the single-sized aggregates. Such observations not only provide insight in the mechanism of these aggregation but provide an opportunity to create nanomaterials which are capable of interacting with their environment, and also communicating this to other particles in the mixture, which could offer new opportunities in biosensing.

\section{Experimental section}

\section{Materials}

All chemicals were used as supplied unless otherwise stated. Methanol, hexane, hydrochloric acid, dichloromethane, toluene, acetone, tetrahydrofuran and diethyl ether were purchased from Fisher Scientific at laboratory reagent grade unless otherwise stated. Deuterochloroform (99.9 atom\% D), 4,4'-azobis(4-cyanovaleric acid) ( $>97.0 \%)$, dodecane thiol $(\geq 98.0 \%)$, potassium phosphate tribasic (reagent grade, $\geq 98.0 \%$ ), carbon disulfide ( $\geq 99.9 \%$ ), 2-bromo-2-methylpropionic acid (98.0\%), $N$-isopropylacrylamide (97.0\%), mesitylene (analytical standard) and magnesium sulfate $(\geq 99.5 \%)$ were all purchased from Sigma-Aldrich. Ultrahigh quality water with a resistance of $18.2 \mathrm{M} \Omega \mathrm{cm}\left(\right.$ at $\left.25^{\circ} \mathrm{C}\right)$ was obtained from a Millipore Milli-Q gradient machine fitted with a $0.22 \mu \mathrm{m}$ filter. Gold nanoparticle solutions for $15 \mathrm{~nm}$ $\left(0.242 \mathrm{mmol} \mathrm{L}^{-1}\right)$ and $40 \mathrm{~nm}\left(0.296 \mathrm{mmol} \mathrm{L}^{-1}\right)$ were purchased from BBI Solutions. Pre-formulated, powdered, phosphate buffered saline was purchased from Sigma-Aldrich, and the desired solution made by addition of ultrahigh quality water to 
give $[\mathrm{NaCl}]=0.137 \mathrm{M},[\mathrm{KCl}]=0.0027 \mathrm{M},\left[\mathrm{Na}_{2} \mathrm{HPO}_{4}\right]=0.01 \mathrm{M}$, $\left[\mathrm{KH}_{2} \mathrm{PO}_{4}\right]=0.0018 \mathrm{M}$ and $\mathrm{pH}=7.4$.

\section{Analytical and physical methods}

${ }^{1} \mathrm{H}$ and ${ }^{13} \mathrm{C}$ NMR spectra were recorded for analysis of monomer conversions and polymer compositions on Bruker DPX-400 spectrometer using deuterated solvents obtained from SigmaAldrich. All chemical shifts are reported in ppm $(\delta)$ relative to tetramethylsilane (TMS). FTIR spectra were acquired using a Bruker Vector 22 FTIR spectrometer with a Golden Gate diamond attenuated total reflection cell. A total 64 (or 128) scans with resolution of $4 \mathrm{~cm}^{-1}$ were collected. Samples were pre-dried as a thin film for FTIR analysis. SEC analysis was conducted on Varian 390-LC MDS system equipped with a column, two PL-AS RT/MT auto sampler, a PL-gel $3 \mathrm{~mm}$ $(50 \times 7.5 \mathrm{~mm})$ guard column, two PL-gel $5 \mathrm{~mm}(300 \times 7.5 \mathrm{~mm})$ mixed-D columns using dimethylformamide (DMF) with $1 \mathrm{mg} \mathrm{mL}^{-1}$ $\mathrm{LiBr}$ at $50{ }^{\circ} \mathrm{C}$ as the eluent at a flow rate of $1.0 \mathrm{~mL} \mathrm{~min}{ }^{-1}$. The GPC system was equipped with ultraviolet (UV) (set at $280 \mathrm{~nm}$ ) and differential refractive index (DRI) detections. Narrow molecular weight poly(methyl methacrylate) (PMMA) standards $\left(200-1.0 \times 106 \mathrm{~g} \mathrm{~mol}^{-1}\right)$ were used for calibration using a second order polynomial fit. Polymer solutions at $1 \mathrm{mg} \mathrm{mL}^{-1}$ were prepared in the eluent and filtered through $0.45 \mathrm{~mm}$ filters prior to injection. UV-vis spectra were recorded in a disposable cuvette using a Cary 60 UV-vis spectrometer from Agilent at $25{ }^{\circ} \mathrm{C}$. Lower critical solution temperatures of free PNIPAM and PNIPAM nanoparticles were also analyzed using a Agilent Cary $60 \mathrm{UV}$-vis spectrometer equipped with a temperature controller at $700 \mathrm{~nm}$ with a heating/cooling rate of $1{ }^{\circ} \mathrm{C} \mathrm{min}{ }^{-1}$. The cloud point of PNIPAM and PNIPAM nanoparticles were determined by normalising the turbidimetry curve such that the values were in the range of 0 to 1 , and the transition temperature was defined as being the temperature corresponding to a normalised absorbance of 0.5 . A polymer concentration of $2.5 \mathrm{mg} \mathrm{mL}^{-1}$ was used in all experiments. DLS and zeta potential measurements were performed using a Nano-Zs from Malvern Instruments, UK running DTS software ( $4 \mathrm{~mW}$, He-Ne laser, $\lambda=633 \mathrm{~nm}$ ) and an avalanche photodiode (APD) detector. The scattered light was measured at an angle of $173^{\circ}$ for DLS measurement and at $12.8^{\circ}$ for zeta potential measurements. The temperature was stabilized to $\pm 0.1{ }^{\circ} \mathrm{C}$ of the set temperature. All samples were prepared at the concentration of $0.029 \mathrm{mg} \mathrm{mL}^{-1}$ gold nanoparticles. Hydrodynamic radii and zeta potential were determined using the manufacturer's software. The size and morphology of the synthesized gold nanoparticles and polymer coated gold nanoparticles were estimated by JEOL 2000FX transmission electron microscopy (TEM) at an accelerating voltage $200 \mathrm{kV}$. A drop of sample solution was deposited onto a copper grid and the water was evaporated under air. No staining was applied. The X-ray photoemission spectroscopy (XPS) data were collected at the Warwick Photoemission Facility, University of Warwick, more details of which are available at reference. ${ }^{32}$ The samples investigated in this study were deposited on to $\mathrm{Cu}$ foil, mounted on to a sample bar and loaded in to a Kratos Axis Ultra DLD spectrometer which possesses a base pressure of $\sim 5 \times 10^{-10}$ mbar. XPS measurements were performed in the main analysis chamber, with the sample being illuminated using an $\mathrm{Al} \mathrm{K} \alpha$ X-ray source. The measurements were conducted at room temperature and at a take-off angle of $\left(30^{\circ}\right)$ with respect to the surface parallel. The core level spectra were recorded using a pass energy of $20 \mathrm{eV}$ (resolution approx. 0.4 eV). The spectrometer work function and binding energy scale were calibrated using the Fermi edge and $3 \mathrm{~d}_{5 / 2}$ peak recorded from a polycrystalline $\mathrm{Ag}$ sample immediately prior to the commencement of the experiments. The data were analysed in the CasaXPS package, using Shirley backgrounds, mixed Gaussian-Lorentzian (Voigt) lineshapes. For compositional analysis, the analyser transmission function has been determined using $\mathrm{Ag}$, $\mathrm{Au}$ and $\mathrm{Cu}$ foils to determine the detection efficiency across the full binding energy range.

\section{Synthesis of 2-(dodecylthiocarbonothioylthio)-2- methylpropanoic acid (DMP)}

Dodecane thiol $(4.00 \mathrm{~g}, 4.73 \mathrm{~mL}, 19.76 \mathrm{mmol})$ was added dropwise to a stirred suspension of $\mathrm{K}_{3} \mathrm{PO}_{4}(4.20 \mathrm{~g}, 19.76 \mathrm{mmol})$ in acetone $(60 \mathrm{~mL})$ over 25 minutes. $\mathrm{CS}_{2}(4.10 \mathrm{~g}, 3.24 \mathrm{~mL}$, $53.85 \mathrm{mmol}$ ) was added and the solution turned bright yellow. After stirring for ten minutes 2-bromo-2-methylpropionic acid $(3.00 \mathrm{~g}, 17.96 \mathrm{mmol})$ was added and a precipitation of $\mathrm{KBr}$ was noted. After stirring for 16 hour, the solvent was removed under reduced pressure and the residue was extracted into $\mathrm{CH}_{2} \mathrm{Cl}_{2}$ $(2 \times 200 \mathrm{~mL})$ from $1 \mathrm{M} \mathrm{HCl}(200 \mathrm{~mL})$. The organic extracts were washed with water $(200 \mathrm{~mL})$ and brine $(200 \mathrm{~mL})$ and further dried over $\mathrm{MgSO}_{4}$. The solvent was removed under reduced pressure and the residue was purified by recrystallization in hexane.

\section{Polymerisation of $\mathrm{N}$-isopropylacrylamide using 2-(dodecylthiocarbonothioylthio)-2-methylpropanoic acid (DMP)}

Polymers with three different molecular weights were synthesised in typical procedure..$^{33} \mathrm{~N}$-Isopropylacrylamide $(1 \mathrm{~g}, 8.84 \mathrm{mmol})$, 2-(dodecylthiocarbonothioylthio)-2-methylpropanoic acid (32.22 mg, $88.4 \mu \mathrm{mol}$ ), and 4,4'-azobis(4-cyanovaleric acid) (ACVA) (4.95 mg, $17.7 \mu \mathrm{mol})$ were dissolved in methanol/toluene $(1: 1 ; 4 \mathrm{~mL})$ in a glass vial containing a stir bar giving [monomer]:[chain transfer agent]:[initiator] $=100: 1: 0.2$. Mesitylene $(150 \mu \mathrm{L})$ was added as an internal reference and the mixture was stirred (5 min). An aliquot of this starting mixture was removed for ${ }^{1} \mathrm{H}$ NMR analysis. The vial was fitted with a rubber septum and degassed by bubbling with nitrogen gas $(30 \mathrm{~min})$. The vial was then placed in an oil bath thermostated at $70{ }^{\circ} \mathrm{C}$. After 35 minutes, the reaction mixture was opened to air and quenched in liquid nitrogen. An aliquot was removed and conversion determined by ${ }^{1} \mathrm{H}$ NMR. The remainder was precipitated into diethyl ether $(45 \mathrm{~mL})$. The polymer was re-precipitated and purified from THF to diethyl ether three times. The product was purified three times by precipitation from toluene into diethyl ether, isolated centrifugation, and dried under vacuum overnight to give a yellow solid. The overall monomer conversion was determined from the ${ }^{1} \mathrm{H}$ NMR spectrum by measuring the decrease in intensity of the vinyl peaks associated with the 
monomer relative to mesitylene. Conversion (NMR): $72 \%$; $M_{\mathrm{n}}$ (theoretical), $8100 \mathrm{~g} \mathrm{~mol}^{-1} ; M_{\mathrm{n}}(\mathrm{SEC}), 7700 \mathrm{~g} \mathrm{~mol}{ }^{-1} ; M_{\mathrm{w}} / M_{\mathrm{n}}$ (SEC), 1.10 .

\section{General procedure for the synthesis of polymer-coated gold nanoparticles}

Approximately $1 \mathrm{mg}$ of the desired thiol-terminated polymer was added to a microcentrifuge tube, and dissolved in $100 \mu \mathrm{L}$ of high-purity water. To this tube was added $900 \mu \mathrm{L}$ of the citratedstabilized gold nanoparticle solution (15 nm: $0.242 \mathrm{mmol} \mathrm{L}^{-1}$, $40 \mathrm{~nm}$ : $0.296 \mathrm{mmol} \mathrm{L}^{-1}$ total gold concentration), which was then agitated overnight in the absence of light. To remove excess polymer, the particles were centrifuged for 30 minutes at $10000 \mathrm{rpm}$. Following careful decantation of the supernatant, the particles were then re-dispersed in $1 \mathrm{~mL}$ of high-quality water and the centrifugation-resuspension process repeated for a total of 3 cycles. After the final cycle the particles were dispersed in $1 \mathrm{~mL}$ of high-quality water for future use. Assuming complete incorporation of the citrate coated gold particles into the final polymer coated particles the total concentration of gold in the final solution was $0.242 \mathrm{mmol} \mathrm{L}^{-1}, 0.048 \mathrm{mg} \mathrm{mL}^{-1}$ and $0.296 \mathrm{mmol} \mathrm{L}^{-1}, 0.058 \mathrm{mg} \mathrm{mL}^{-1}$.

\section{Acknowledgements}

SW thanks the University of Warwick for the award of a Chancellors International Scholarship. Equipment used was supported by the Innovative Uses for Advanced Materials in the Modern World (AM2), with support from Advantage West Midlands (AWM) and part funded by the European Regional Development Fund (ERDF). MIG holds an ERC starter grant (CRYOMAT 638661).

\section{References}

1 R. S. Lee, Y. T. Huang and W. H. Chen, J. Appl. Polym. Sci., 2010, 118, 1634.

2 E. S. Gill and S. M. Hudson, Prog. Polym. Sci., 2004, 29, 1173.

3 F. D. Jochum and P. Theato, Chem. Commun., 2010, 46, 6717.

4 A. Kumar, I. Y. Galaev and B. Mattiasson, Biotechnol. Bioeng., 1998, 59, 695.

5 (a) T. Shiga, Adv. Polym. Sci., 1997, 134, 131; (b) G. Filipcsei, J. Feher and M. Zrinyi, J. Mol. Struct., 2000, 554, 109.

6 M. Zrinyi, Colloid Polym. Sci., 2000, 278, 98.

7 T. Miyata, N. Asami and T. Uragami, Nature, 1999, 399, 766.

8 B. Jeong, K. M. Lee, A. Gutowska and Y. H. An, Biomacromolecules, 2002, 3, 865.

9 (a) A. Hatefi and B. Amsden, J. Controlled Release, 2002, 80, 9; (b) B. Jeong, Y. H. Bae, D. S. Lee and S. W. Kim, Nature, 1997, 388, 860.

10 H. Wei, S. X. Cheng, X. Z. Zhang and R. X. Zhuo, Prog. Polym. Sci., 2009, 34, 893.
11 (a) S. Y. Yang and M. F. Rubner, J. Am. Chem. Soc., 2002, 124, 2100; (b) X. Z. Shu, K. J. Zhu and W. Song, Int. J. Pharm., 2001, 212, 19.

12 (a) M. Ebara, M. Yamato, M. Hirose, T. Aoyagi, A. Kikuchi, K. Sakai and T. Okano, Biomacromolecules, 2003, 4, 344; (b) M. Yamato, C. Konno, A. Kushida, M. Hirose, M. Utsumi, A. Kikuchi and T. Okano, Biomaterials, 2000, 21, 981; (c) M. A. Nandkumar, M. Yamato, A. Kushida, C. Konno, M. Hirose, A. Kikuchi and T. Okano, Biomaterials, 2002, 23, 1121; (d) K. Uchida, K. Sakai, E. Ito, O. H. Kwon, A. Kikuchi, M. Yamato and T. Okano, Biomaterials, 2000, 21, 923.

13 (a) A. Chilkoti, M. R. Dreher, D. E. Meyer and D. Raucher, Adv. Drug Delivery Rev., 2002, 54, 613; (b) J. Weidner, Drug Discovery Today, 2001, 6, 1239; (c) D. E. Meyer, G. A. Kong, M. W. Dewhirst, M. R. Zalutsky and A. Chilkoti, Cancer Res., 2001, 61, 1548.

14 (a) J. M. Hu, X. Z. Zhang, D. Wang, X. L. Hu, T. Liu, G. Y. Zhang and S. Y. Liu, J. Mater. Chem., 2011, 21, 1903; (b) Y. Z. You, K. K. Kalebaila, S. L. Brock and D. Oupicky, Chem. Mater., 2008, 20, 3354; (c) M. R. Islam, A. Ahiabu, X. Li and M. J. Serpe, Sensors, 2014, 14, 8984.

15 (a) H. G. Schild, Prog. Polym. Sci., 1992, 17, 163; (b) F. M. Winnik, Polymer, 1990, 31, 2125; (c) F. Meersman, J. Wang and Y. Q. Wu, Macromolecules, 2005, 38, 8923; (d) G. LunaBarcenas, D. G. Gromov, J. C. Meredith, I. C. Sanchez, J. J. dePablo and K. P. Johnston, Chem. Phys. Lett., 1997, 278, 302.

16 (a) M. Heskins and J. E. Guillet, J. Macromol. Sci., Chem., 1968, 2, 1441; (b) Y. Hirokawa and T. Tanaka, J. Chem. Phys., 1984, 81, 6379; (c) C. Wu and S. Q. Zhou, Macromolecules, 1995, 28, 5388; (d) K. Akiyoshi, E. C. Kang, S. Kurumada, J. Sunamoto, T. Principi and F. M. Winnik, Macromolecules, 2000, 33, 3244 .

17 H. G. Schild and D. A. Tirrell, J. Phys. Chem., 1990, 94, 4352Chain length, salt.

18 Y. Xia, X. Yin, N. A. D. Burke and H. D. H. Ströver, Macromolecules, 2005, 38, 5937.

19 S. Fujishige, K. Kubota and I. Ando, J. Phys. Chem., 1989, 93, 3311.

20 Y. J. Zhang, S. Furyk, D. E. Bergbreiter and P. S. Cremer, J. Am. Chem. Soc., 2005, 127, 14505.

21 L. D. Blackman, D. B. Wright, M. P. Robin, M. I. Gibson and R. K. O'Reilly, ACS Macro Lett., 2015, 4, 1210.

22 (a) N. Nath and A. Chilkoti, J. Am. Chem. Soc., 2001, 123, 8197; (b) R. A. Sperling, P. Rivera Gil, F. Zhang, M. Zanella and W. J. Parak, Chem. Soc. Rev., 2008, 37, 1896; (c) A. Kumar, X. Zhang and X.-J. Liang, Biotechnol. Adv., 2013, 31, 593.

23 (a) A. N. Shiway, E. Katz and I. Willner, ChemPhysChem, 2000, 1, 18; (b) F. Remacle and R. D. Levine, ChemPhysChem, 2001, 2, 20; (c) A. C. Templeton, W. P. Wuelfing and R. W. Murray, Acc. Chem. Res., 2000, 33, 27; (d) S.-J. Richards and M. I. Gibson, ACS Macro Lett., 2014, 3, 1004; (e) S.-J. Richards, L. Otten and M. I. Gibson, J. Mater. Chem. B, 2016, 4, 3046.

24 (a) F. Mastrotto, P. Caliceti, V. Amendola, S. Bersani, J. P. Magnusson, M. Meneghetti, G. Mantovani, C. Alexander and S. Salmaso, Chem. Commun., 2011, 47, 984; (b) S. Lv, C. Cehng, Y. Song and Z. Zhao, RSC Adv., 2015, 5, 3248. 
25 M. S. Yavuz, J. Cheng, C. M. Cobley, Q. Zhang, M. Rycenga, J. Xie, C. Kim, K. H. Song, A. G. Schwartz, L. V. Wang and Y. Xia, Nat. Mater., 2009, 8, 935.

26 (a) F. Fernández-Trillo, J. C. M. van Hest, J. C. Thies, T. Michon, R. Weberskirch and N. R. Cameron, Chem. Commun., 2008, 2230; (b) F. Fernández-Trillo, J. C. M. van Hest, J. C. Thies, T. Michon, R. Weberskirch and N. R. Cameron, Adv. Mater., 2009, 21, 55.

27 (a) M. I. Gibson, D. Paripovic and H.-A. Klok, Adv. Mater., 2010, 22, 4721; (b) N. S. Ieong, M. Hasan, D. J. Phillips, Y. Saaka, R. K. O'Reilly and M. I. Gibson, Polym. Chem., 2012, 3, 794.

28 R. L. M. Teeuwen, F. A. de Wolf, H. Zuilhof and J. C. M. van Hest, Soft Matter, 2009, 5, 4305.
29 (a) D. J. Phillips and M. I. Gibson, Chem. Commun., 2012, 48, 1054; (b) Z. Li, Y.-H. Kim, H. S. Min, C.-K. Han and K. M. Huh, Macromol. Res., 2010, 18, 618.

30 Z. Zhang, S. Maji, A. B. da F. Antunes, R. D. Rycke, Q. Zhang, R. Hoogenboom and B. G. D. Geest, Chem. Mater., 2013, 25, 4297.

31 (a) N. S. Ieong, K. Bebis, L. E. Daniel, R. K. O'Reilly and M. I. Gibson, Chem. Commun., 2011, 47, 11627; (b) M. I. Gibson and R. K. O'Reilly, Chem. Soc. Rev., 2013, 42, 7204; (c) D. J. Phillips and M. I. Gibson, Polym. Chem., 2015, 6, 1033.

32 See http://go.warwick.ac.uk/XPS.

33 D. J. Phillips and M. I. Gibson, Biomacromolecules, 2012, 13, 3200 . 